\title{
Geração de energia elétrica através da energia hidráulica e seus impactos ambientais
}

\author{
Production of electrical power through hydraulic energy and its environmental impacts \\ Rosemar de Queiroz', Patrícia Grassi', Kariane Lazzare', Ezequiel Koppe², \\ Bruna Rampon Tartas', Pedro Daniel da Cunha Kemerich ${ }^{3}$. \\ ' Acadêmica do curso de Engenharia Ambiental; UFSM; Linha Sete de Setembro, BR386, km 40, Frederico Westphalen, 98400-000; \\ ${ }^{2}$ Eng. Agr. Mestrando do Programa de Pós Graduação em Agronomia: Agricultura e Ambiente; \\ ${ }^{3}$ Professor do Curso de Engenharia Ambiental - UFSM/CESNORS.
}

\section{Resumo}

Este trabalho teve por objetivo fazer uma revisão bibliográfica de como a energia elétrica é gerada a partir das usinas hidrelétricas e os impactos ambientais trazidos por esse tipo de empreendimento. A energia hidráulica é produzida através da força do movimento das águas, por meio das usinas hidrelétricas. Os principais fatores que influenciam na geração dessa energia são: a vazão do rio, a quantidade de água disponível em determinado período de tempo e os desníveis do relevo, sejam eles naturais, como as quedas d'água, ou criados artificialmente. A energia hidráulica, apesar de ter uma parcela significativa das fontes de energia mundial, é geradora de impactos, tais como: socioeconômicos, culturais e ambientais prejudicando a fauna, a flora e a comunidade ribeirinha do local. Mas esses impactos são relevantes já que podem ser facilmente corrigidos, com uma boa assessoria ambiental e social, e uma parcela dos custos do investimento destinados à mesma. Antes da implantação desse empreendimento, é importante se fazer um plano de ações a fim de minimizar os impactos causados.

Palavras-chave: energia elétrica; energia hidráulica; impactos ambientais

\begin{abstract}
This paper aimed makes a bibliographic review of how the electric energy is generated by hydropower plants and the environmental injuries by this kind of enterprise. The hydraulic energy is produced through the power of water movement, by hydropower plants. The main factors that influence the generation of this energy are: river's flow, quantity of available water in a determined period of time and the difference in level, being them naturals, like waterfalls, or created artificially. Although of a significantly portion of contribution in world energy matrix, hydraulic energy causes several socioeconomic impacts, as great areas waterlogging injuring flora, fauna and the community that lives around the river. However this impacts are important whereas can be easily corrected, with a good environmental and social assistance, and a part of the investment coasts destined to it. Before the implantation of this enterprise, it's important make and action plan aiming reduce the impacts caused.
\end{abstract}

Keywords: electricity, hydropower, environmental impacts. 


\section{INTRODUÇÃO}

Levando em consideração o aumento relevante na demanda de energia elétrica pela população, para os mais variados fins, se faz necessário novos investimentos para suprir esta necessidade. Uma das alternativas mais utilizadas na geração de energia elétrica é a energia hidráulica. Entretanto, apesar da grande disponibilidade de recursos hídricos no Brasil, a criação de usinas hidrelétricas vem gerando impactos tanto ambientais, quanto sociais, obrigando o abastecimento de energia a depender cada vez mais de fontes térmicas, caras e poluentes, apesar de também causarem inúmeros impactos ambientais provocados por esse tipo de energia (ABBUD; TANCREDI, 2010).

As características físicas, geográficas e a grande disponibilidade de recursos hídricos no Brasil, foram determinantes para que o país fosse hoje, o terceiro maior potencial hidráulico do mundo. Em termos absolutos, os cinco maiores produtores desse tipo de energia são Canadá, China, Brasil, Estados Unidos e Rússia (CERPCH, 2011).

A energia hidráulica é produzida através da força do movimento das águas. Para que isso seja possível, há alguns fatores que influenciam na geração de energia elétrica. Os principais fatores de influencia são: a vazão do rio, a quantidade disponível de água em diversos períodos do ano, a topografia, as alterações antrópicas, ou naturais, como as quedas de água naturais, ou criadas artificialmente (ANEEL, 2008).

As usinas hidrelétricas são compostas, basicamente, por barragem, casa de força, vertedouro e sistema de captação e adução de água, sendo que funcionam em conjunto e de maneira integrada. A barragem interrompe o curso normal do rio e desvia para um determinado local formando grandes reservatórios, que estocam a água e permitem a formação de grandes quedas. Estas produzem força, que é utilizada para movimentar turbinas e acionar o gerador elétrico (PANZERA, GOMES e MOURA, 2010).

Porém, a energia hidráulica também gera graves impactos negativos. Pois influenciam diretamente no meio ambiente devido à construção das represas, que provocam inundações em imensas áreas de matas, interferindo no fluxo de rios, destroem espécies vegetais, prejudicam a fauna, e interferem na ocupação humana. As inundações das florestas fazem com que as plantas de cobertura do solo entrem em processo de decomposição, com isso a biodiversidade local é afetada, e ocorre a liberação de metano na atmosfera, sendo que este é um dos gases responsáveis pelo efeito estufa e pela rarefação da camada de ozônio (INATOMI; UDAETA, 2005).

O objetivo deste trabalho é apresentar uma revisão bibliográfica de como a energia elétrica é gerada a partir das usinas hidrelétricas e os impactos ambientais causados por esse tipo de empreendimento.

\section{REFERENCIAL TEÓRICO}

\section{ENERGIA HIDRÁULICA}

Segundo Bortoleto (2001), a energia hidráulica provem da condensação, precipitação e evaporação das águas, fatores estes causados pela irradiação solar e pela energia gravitacional, sendo estes os responsáveis pela geração de energia hidráulica. As usinas hidrelétricas tem a capacidade de transformar energia cinética em energia elétrica a partir do aproveitamento do movimento das águas.

Segundo o Atlas Nacional de Energia Elétrica, publicado pela Agência Nacional de Energia Elétrica 2002, uma das primeiras formas de substituir o trabalho animal pelo mecânico, foi através do bombeamento de água para a moagem de grãos. Que tinha como vantagem a grande disponibilidade de recursos, o fácil acesso, a simplicidade de aproveitamento, e especialmente renovável.

Nos anos 60, com o objetivo de desenvolver políticas de implantação de grandes projetos hidrelétricos, desenvolveu-se a Eletrobrás (Centrais elétricas Brasileiras SA), responsável por projetos hidrelétricos como Sobradinho, Balbina, Itaipu Binacional e Itaparica. A Eletrobrás, ao desenvolver seu papel de holding, atribuiu tarefas de execução de projetos de geração de energia a algumas subsidiárias. Em tese, as empresas designadas para desenvolver funções, deveriam ficar limitadas a

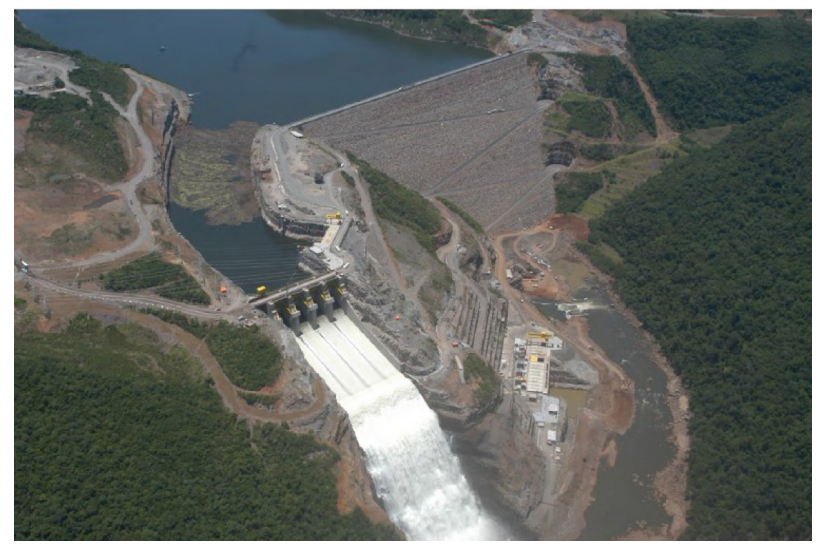

Figura 1: Usina Hidrelétrica.

Fonte: ARTEAGA, 2010. 
distribuir energia, segundo o plano do estado. Desta forma a centralização torna-se compatível com as audaciosas propostas pelos governos militares (SANTOS, 2003).

Segundo Ruth (2010), nos anos 70, ao desenvolver novas tecnologias, foi possível permitir a implantação de linhas de transmissão de longas distancias, tornando possível o uso de recursos hidráulicos em regiões remotas. Já, nos anos 90, devido ao aumento da privatização do setor elétrico brasileiro, passou a ser estimulada pelo governo a formação de consórcios privados, para a implantação de usinas planejadas. A impessoalidade dos projetos e a rapidez com que ocorreram, dificultaram os movimentos de repressão às usinas hidrelétricas, gerando insegurança as populações afetadas (SANTOS, 2003).

\section{I.I ESTRUTURA DE UMA USINA HIDRELÉTRICA}

A estrutura de uma usina hidrelétrica funciona de maneira integrada e em conjunto, e é formada principalmente, pelo sistema de captação e adução de água, pela barragem e pela casa de força e vertedouro. A função da barragem é interromper o curso normal da água, criando um reservatório, onde será armazenada a água. Além de armazenar água, este reservatório também permite que a vazão dos rios seja adequada, tanto em períodos chuvosos, quanto de estiagem, a captação da chuva em volume adequado e uma diferença de

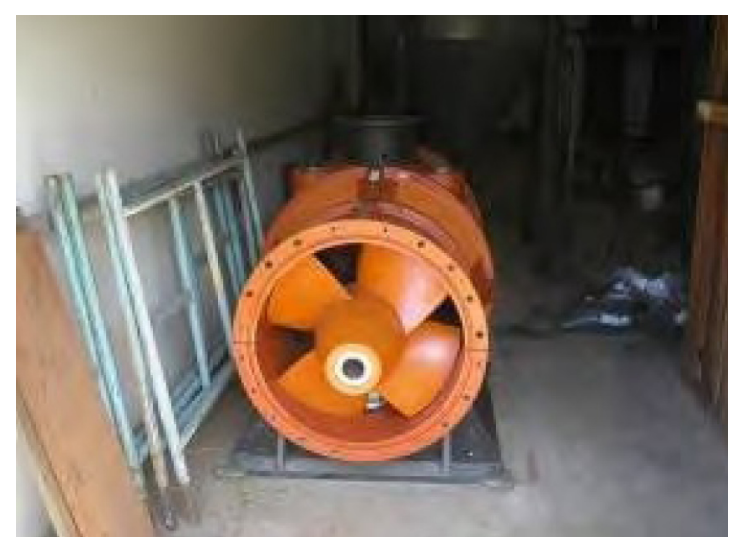

Figura 2: Turbinas das usinas hidrelétricas.

Fonte: ARTEAGA,2010.

altura que PE necessária para a geração da energia hidráulica (ANEEL, 2005).

Segundo Oliveira (2009), as usinas hidrelétricas que não possuem reservatório, ou o possuem em dimensões menores, são "hidrelétricas a fio d'água", os seja, este tipo de hidrelétrica utiliza a velocidade das águas dos rios, para gerar energia. A ausência de reservatório faz com que em épocas de seca, seja reduzida a capacidade energética produzida pela hidrelétrica, ou em alguns casos, seja desativada em determinados períodos do ano. Os processos de captação e adução se dão por túneis, canais ou condutos metálicos, que levam a água até a casa de força. Na casa de força estão localizadas as turbinas, constituídas por uma série de pás

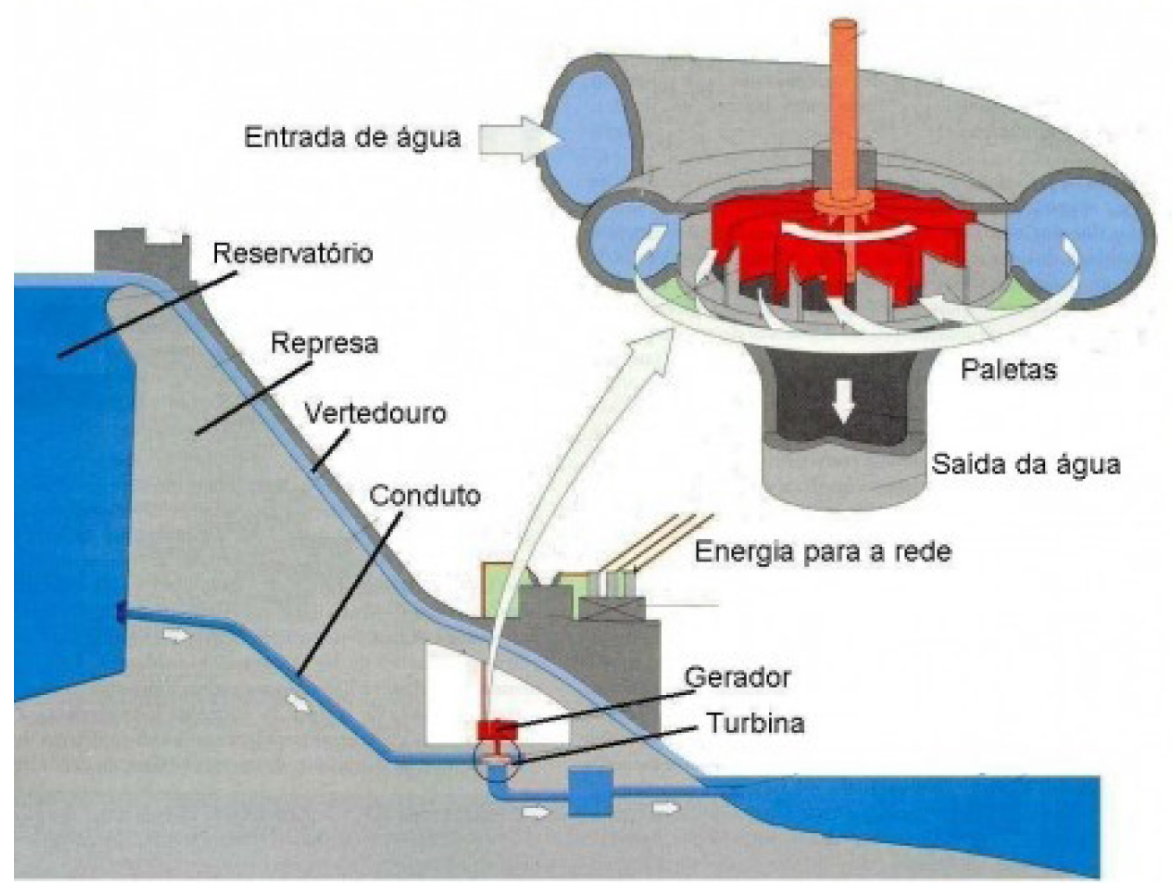

Figura 3: Esquema de como funciona uma usina hidrelétrica.

Fonte: Infoescola. 
ligadas ao um eixo, sendo que este está conectado ao gerador. Com eficiência que pode chegar a 90\%, as turbinas hidráulicas são atualmente as formas mais eficientes de conversão de energia primária em energia secundária (figura 2).

As turbinas transformam energia cinética, originada do movimento das águas em energia elétrica, durante o movimento giratório das turbinas, que conectadas a geradores produzirão energia elétrica. Após passar pelas turbinas, a água é devolvida ao seu leito natural do rio, através do canal de fuga (CICOGNA, 2003). Segundo o Atlas Nacional de Energia Elétrica, publicado pela Agência Nacional de Energia Elétrica (ANEEL) em 2008, o vertedouro, cuja finalidade é permitir a saída de água quando os reservatórios estiverem com os níveis acima do recomendado. O que pode ocorrer devido ao excesso de chuva, ou de vazão. Mais água no reservatório do que o necessário para a geração de energia é outro motivo para a abertura dos vertedouros. Em épocas chuvosas, o vertedouro é aberto para evitar enchentes nas suas proximidades. Podem-se definir vertedouros, como dique, paredes, ou aberturas as quais o liquido escoa. Pode ser aplicado também aos extravasores das represas ou aos obstáculos das correntes de água (FERNADEZ; ARAUJO; ITO; 2009).

\section{I.2 ETAPAS PARA A INSTALAÇAO DE UMA USINA HIDRELÉTRICA}

A primeira etapa da instalação de uma usina hidrelétrica consiste em fazer um inventário da bacia hidrográfica. O objetivo dessa etapa é determinar que aproveitamento da bacia, que será necessário para geração de energia elétrica, segundo o conceito de aproveitamento ótimo, estabelecida pela Lei ${ }^{\circ}$. 9.074, de 1995. Os inventários podem ser feitos por quaisquer agentes privados ou pela própria empresa de pesquisa energética (EPE), mediante registro junto à ANEEL, que autoriza a sua realização por despacho (ABBUD; TANCREDI, 2010).

Depois de realizado o estudo de inventário, realiza-se outro de aproveitamento hidrelétrico. Este tem por finalidade a definição da concepção global de um dado aproveitamento da melhor alternativa de divisão de queda estabelecida na etapa de inventário. Nessa etapa são providenciados os estudos socioambientais (EIA/RIMA) necessários à obtenção de Licença Ambiental Prévia. A qual compreende o dimensionamento do aproveitamento, as obras de infraestrutura local e regional, o dimensionamento do reservatório e da área de influencia, bem como as ações necessárias para a sua implantação (SOUZA, 2000).

Os estudos ambientais e sociais devem ser enviados aos órgãos que concedem o licenciamento ambiental para que se consiga a licença previa. Caso haja necessidade de sua anuência este órgão, por sua vez, os encaminha a outros órgãos (FUNAI, IPHAN etc.) Para poder ser leiloado o aproveitamento energético é preciso obter, ainda nessa fase, a Reserva de Disponibilidade Hídrica junto à Agência Nacional de Águas (ANA), que, mais tarde, transformar-se-á numa outorga de uso da água (ABBUD; TANCREDI; 2010).

Depois de leiloado o aproveitamento hidrelétrico, vem a fase de elaboração do projeto básico e dos programas e projetos socioambientais. No projeto básico o aproveitamento é detalhado e definido seu orçamento com maior precisão, de forma a permitir ao vencedor da licitação de concessão a implantação do empreendimento. Nessa etapa realiza-se, também, o Projeto Básico Ambiental. Já no projeto executivo, se processam a elaboração dos desenhos de detalhamento das obras civis e dos equipamentos hidromecânicos e eletromecânicos, necessários à execução da obra e à montagem dos equipamentos. Nesta fase são decidias as ações preventivas necessárias para a implantação do reservatório (SOUZA, 2000).

O órgão responsável pela aprovação do projeto básico e autorização da construção da usina é ANEEL, é o órgão que concede o licenciamento ambiental que emite a chamada Licença de Instalação, se concordar com os programas e projetos elaborados. Só então pode começar a construção da usina, sob a fiscalização da ANEEL. Antes da entrada em operação, o empreendedor precisa obter, ainda, a chamada Licença de Operação, a última exigida, que é condição para o enchimento do reservatório. Portanto, entre o início dos estudos de viabilidade e a operação de uma usina hidroelétrica, transcorrem, no mínimo, seis anos, podendo chegar a treze anos (ABBUD; TANCREDI; 2010).

\section{I.3 MATRIZ ENERGÉTICA DA ENERGIA HIDRÁULICA}

A energia hidráulica, diferente das demais fontes renováveis, representa uma significativa parcela da matriz energética mundial, possuindo tecnologias de aproveitamento consolidadas. Em muitos países é a principal fonte de energia elétrica, e conforme mostra na figura 4 , esse tipo de energia representa aproximadamente $2,1 \%$ da geração total de energia elétrica mundial, e $2,1 \%$ da matriz nacional (Revista cultura e cidadania 2012). 

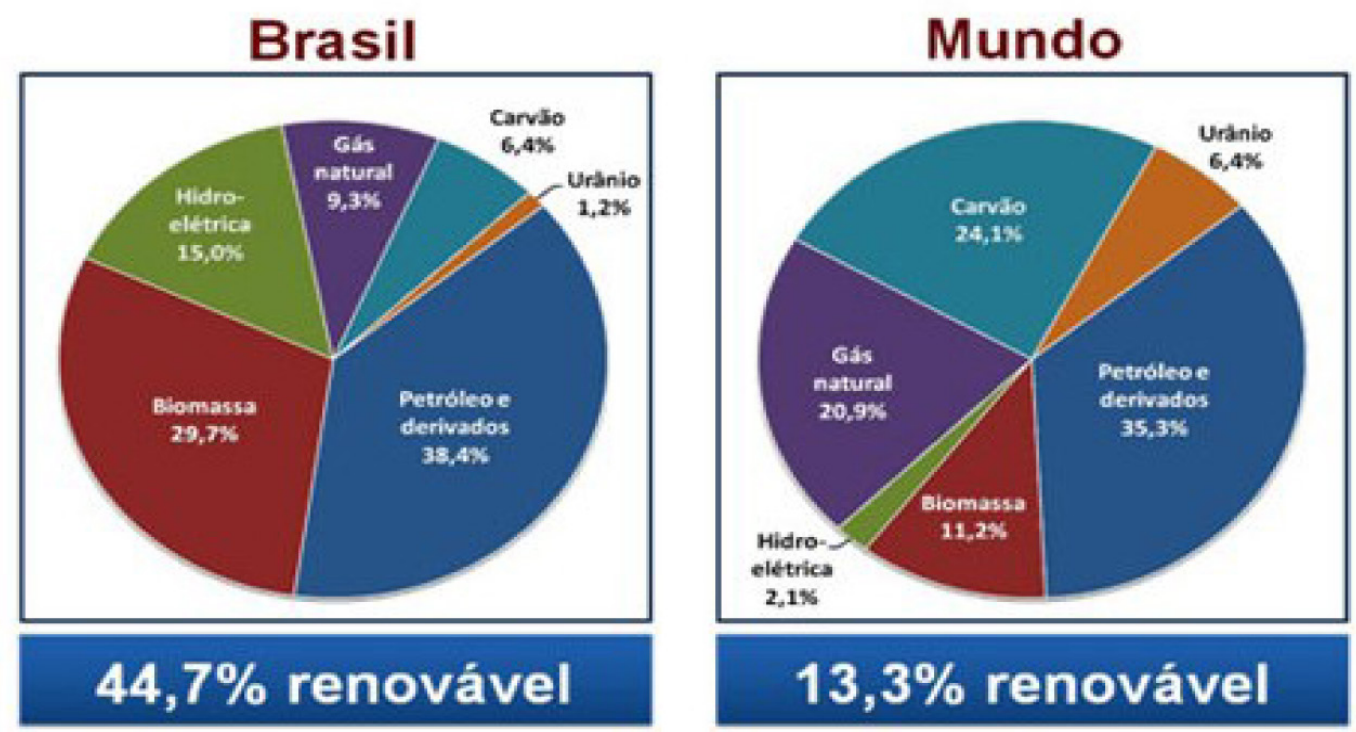

Figura 4: Matriz energética mundial e nacional.

Fonte: Revista cultura e cidadania 2012.

\begin{tabular}{|l|r|r|r|r|r|r|r|r|r|r|}
\hline \multicolumn{1}{|c|}{ Origem/Ano } & \multicolumn{1}{c|}{$\mathbf{2 0 0 8}$} & \multicolumn{1}{|c|}{$\mathbf{2 0 0 9}$} & $\mathbf{2 0 1 0}$ & $\mathbf{2 0 1 1}$ & $\mathbf{2 0 1 2}$ & $\mathbf{2 0 1 3}$ & $\mathbf{2 0 1 4}$ & $\mathbf{2 0 1 5}$ & $\mathbf{2 0 1 6}$ & $\mathbf{2 0 1 7}$ \\
\hline Hidrelétrica & 84,9 & 86,8 & 89,9 & 91,8 & 92,5 & 95,4 & 98,2 & 103,6 & 111,0 & 117,5 \\
Termelétrica & 14,9 & 17,3 & 22,1 & 24,8 & 25,6 & 30,8 & 30,8 & 31,7 & 31,7 & 31,7 \\
Eólica/Outras & & & & & & & & & & \\
FA & 0,3 & 1,0 & 1,4 & 1,4 & 1,4 & 1,4 & 1,4 & 1,7 & 2,1 & 2,1 \\
Nuclear & 2,0 & 2,0 & 2,0 & 2,0 & 2,0 & 2,0 & 3,4 & 3,4 & 3,4 & 3,4 \\
\hline \multicolumn{1}{|c|}{ SOMA } & $\mathbf{1 0 2 , 0 8}$ & $\mathbf{1 0 7 , 1 9}$ & $\mathbf{1 1 5 , 4 8}$ & $\mathbf{1 2 0 , 0 7}$ & $\mathbf{1 2 1 , 5 3}$ & $\mathbf{1 2 9 , 6 2}$ & $\mathbf{1 3 3 , 8 3}$ & $\mathbf{1 4 0 , 4 5}$ & $\mathbf{1 4 8 , 1 1}$ & $\mathbf{1 5 4 , 6 5}$ \\
\hline
\end{tabular}

Figura 5: Evolução Prevista da Matriz de Energia Elétrica - 2008/2017 em mil MW.

Fonte: (ABBUD; TANCREDI; 2010). Transformações recentes da matriz brasileira de geração de energia elétrica - causas e impactos principais.

Segundo o Balanço Energético Nacional (2003) embora a tendência ao aumento de outras fontes de energias seja grande, devido a fatores socioeconômicos e ambientais que restringem projetos hidrelétricos e aos avanços tecnológicos no aproveitamento de novas fontes de energia, a probabilidade e de que a energia hidráulica continue sendo a principal fonte energética no Brasil pelos próximos anos. Embora os locais de maior potencial gerador de energia elétrica se encontrar em áreas de preservação ambiental, e longe dos grandes centros, supõem-se que, futuramente, pelo menos $50 \%$ da necessidade de crescimento energético se dará através de origem hídrica, como podemos observar na figura 5 (ANEEL,2002).

\section{POTENCIAL HIDRELÉTRICO DO BRASIL}

Fazendo parte de quase todas as atividades dos seres vivos, a água possui um valor incomparável, principalmente para os seres humanos, os quais dependem desta tanto para a produção de alimentos, quanto para geração de energia. Com $13,8 \%$ da quantidade de água doce disponível no planeta, o Brasil é o país que possui a maior disponibilidade hídrica mundial. Com $182.170 \mathrm{~m}^{3} / \mathrm{s}$ de produção hídrica em todo o território nacional, o que equivale a $5.744 \mathrm{~km}^{3}$ anuais. Se levar em consideração o montante das vazões geradas nas bacias da Amazônia, Paraná, Uruguai e Paraguai, localizados fora do território nacional, estimam-se $76.580 \mathrm{~m}^{3} / \mathrm{s}$, o que somado a quantidade pertencente ao território nacional chega a $258.750 \mathrm{~m}^{3} / \mathrm{s}$ (FREITAS, 2001).

Segundo Abbud e Tancredi (2010), o potencial energético do Brasil é uma das suas maiores riquezas, devido a grande disponibilidade hídrica, o que fornece a de geração de energia renovável. De acordo com a ultima pesquisa mundial realizada, 
o Brasil apresenta o maior potencial hidrelétrico do mundo, e deste, $50 \%$ ainda esta a ser explorado.

Segundo Facuri (2004), no que se trata de aproveitamento energético, o Brasil apresenta uma variação de região pra região (figura 6). Esse aproveitamento sofre influencia direta do relevo. Na região centro-sul do Brasil, há grande utilização dos recursos hídricos como potencial gerador de energia elétrica, isso influenciado por um relevo apropriado (planaltos), e a um desenvolvimento econômico acelerado. Já na região do Amazonas, os índices de aproveitamento energético são menores, devido a uma rica diversidade de fauna e flora, ao relevo (planícies), que não apresenta as caracte- rísticas naturais necessárias, e por estar longe dos grandes centros consumidores de energia elétrica. Porem, com os melhores potências hidrelétricos das regiões Sudeste e Sul se esgotando, e com processo de interiorização do país, estima-se que nas regiões remotas e menos desenvolvidas haverá maior aproveitamento dos potenciais hidráulicos.

No setor energético a geração hidrelétrica garante a produção de aproximadamente 91\% da eletricidade consumida no Brasil. O potencial hidrelétrico brasileiro é de aproximadamente 260 GW dos quais se encontram em operação apenas 22\%(57 GW) (ANEEL, 2008).

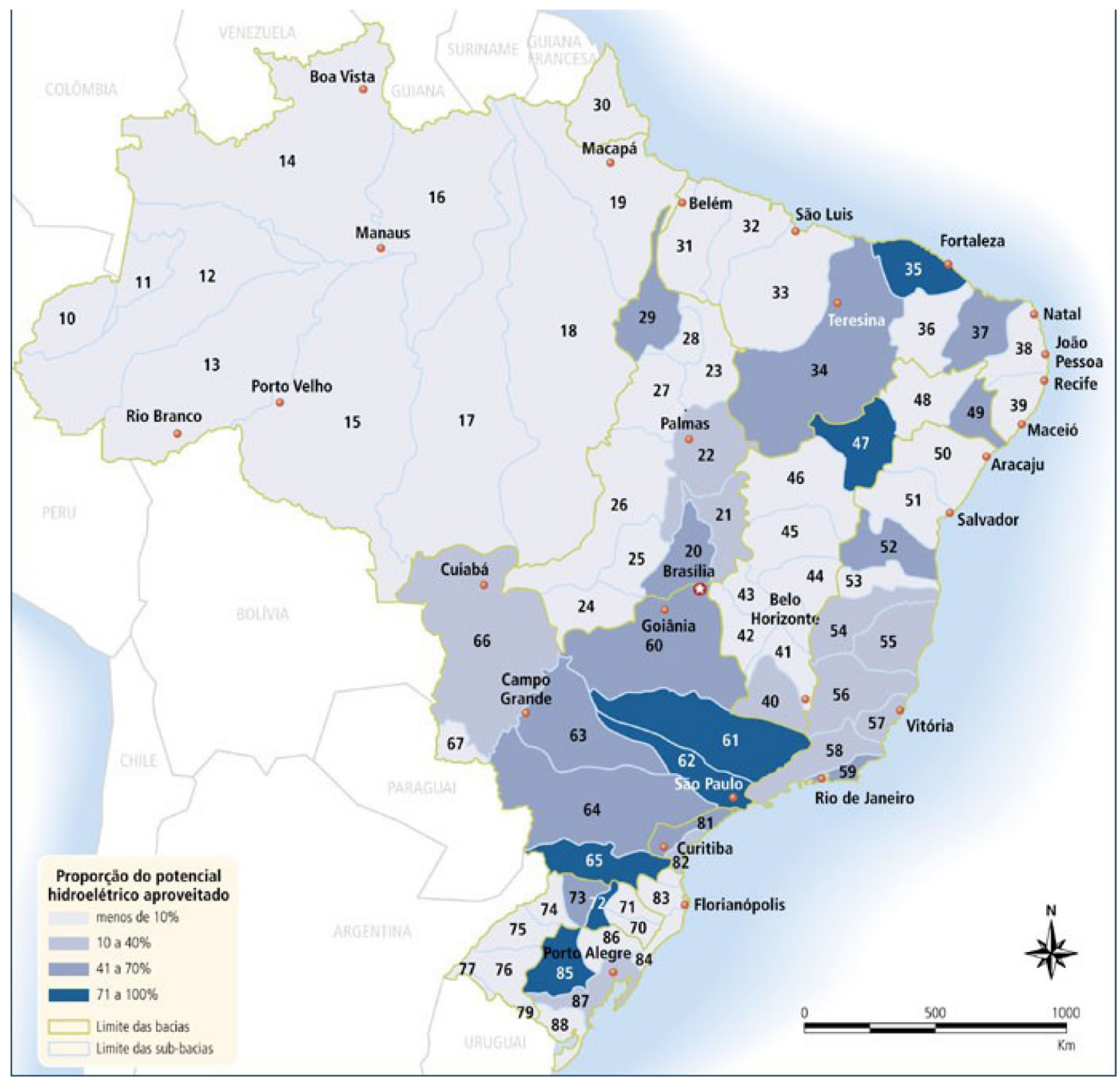

Figura 6: Taxa de aproveitamento do potencial hidrelétrico brasileiro. Fonte: ANEEL. 


\section{I LOCALIZAÇÃO DAS USINAS HIDRELÉTRICASS NO BRASIL}

A maior parte das usinas hidrelétricas e operação no Brasil (pontos verdes), estão localizadas nas regiões Sudeste-Centro-Oeste do Brasil, assim como mostra a figura 7, onde se localiza o centro de carga do sistema, e que há um grande número de usinas previstas (pontos vermelhos) e em estudo (pontos laranja) na região norte do país, como podemos observar na figura (CANTARANI; BIANCHI; 2009).

\subsection{DEMANDA DE ENERGIA HIDRÁULICA}

O Brasil terá que investir pesado na expansão da oferta da energia elétrica, devido a crescente demanda nesse setor, sendo que em 2030 estima-se um consumo entre 950 e $1.250 \mathrm{TWh} /$ ano. No caso deste fornecimento ser realizado por usinas hidrelétricas, mesmo com uma instalação adicional de 120 mil MW, o que eleva para $80 \%$ o uso do potencial, ainda assim poderia não ser suficiente para atender a demanda em 2030. Na figura 8, pode visualizar-se a projeção da demanda e da produção de energia elétrica por fonte hidráulica (BRONZATTI; NETO; 2008).

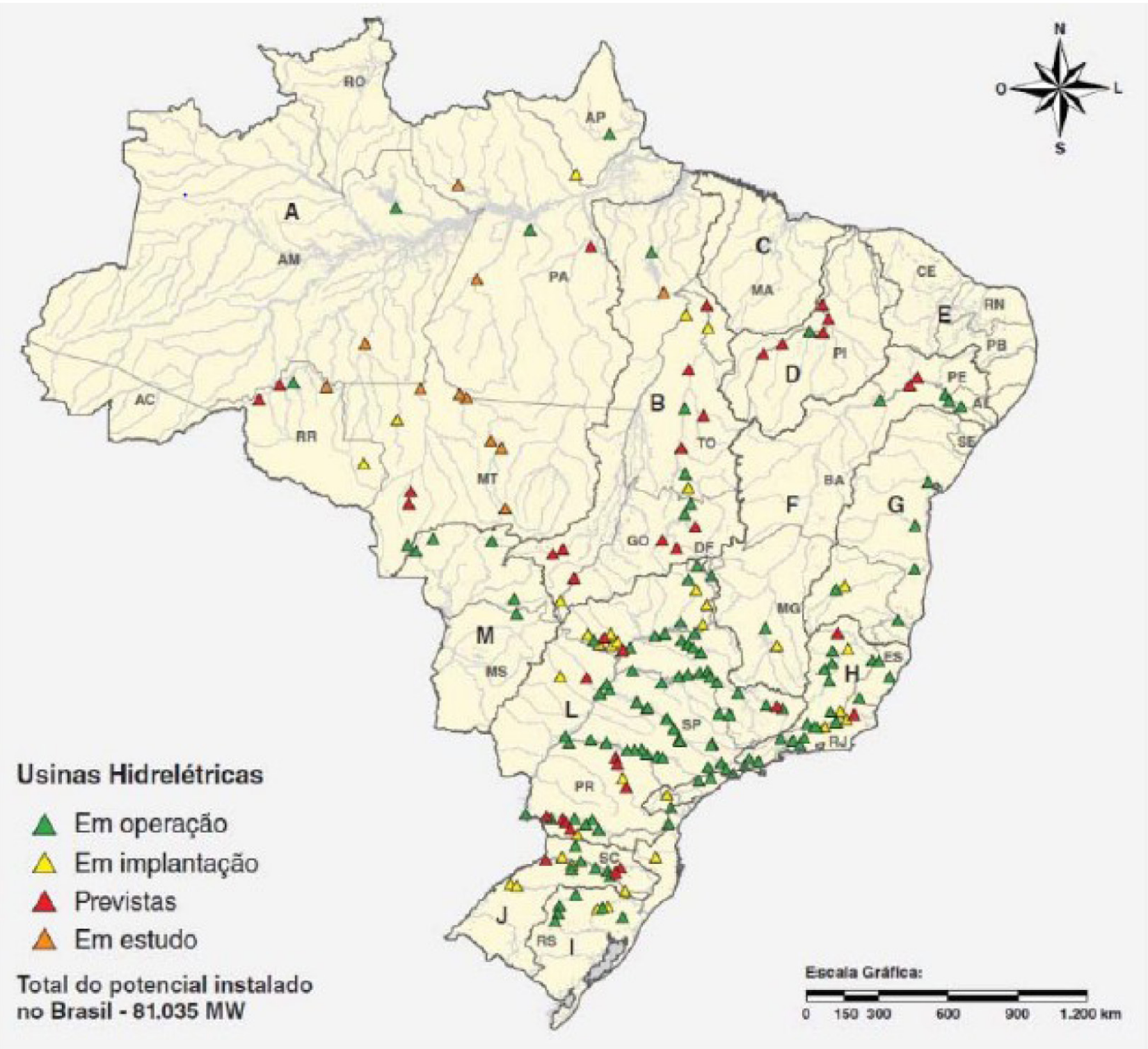

3.

Figura 7: Localização das hidrelétricas no Brasil. Fonte: . CANTARANI C; BIANCHI A.JR, 2004. ANA 2009. 


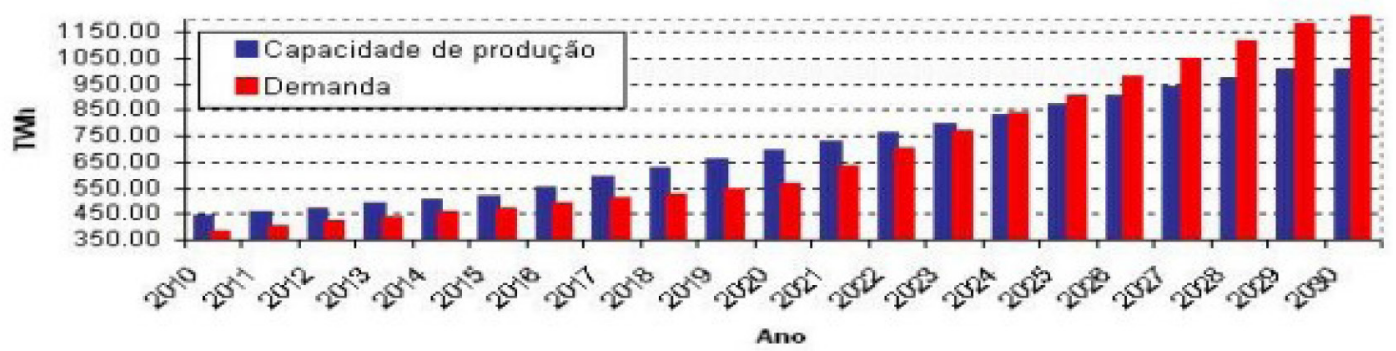

Figura 8: Demanda de energia hidrelétrica para fonte hidráulica Fonte: MATRIZES ENERGÉTICAS NO BRASIL: CENÁRIO 2010-2030

\section{IMPACTO AMBIENTAL}

Segundo a Resolução 01/1986 do Conselho Nacional do Meio Ambiente (Conama), impacto ambiental é toda mudança das características físicas, biologicas ou químicas do meio ambiente, gerada por qualquer ação humana, que cause danos a sociedade e ao meio ambiente, direta ou indiretamente.

O estudo dos impactos ambientais permite avaliar as consequências de algumas ações, para que possa haver a prevenção da qualidade de determinado ambiente que poderá sofrer a execução de certos projetos ou ações, ou logo após a implantação dos mesmos (SOARES, 2013).

O CONAMA surgiu na década de 80 , que através da Resolução 001/86 fixou os requisitos para a avaliação de impactos e para o licenciamento de obras modificadoras do meio ambiente, entre elas as do setor elétrico como as usinas hidrelétricas. Tornaram-se obrigatórios o EIA (estudo de impacto ambiental) e o RIMA (relatório de impacto ambiental). A partir daí, novas discussões legais emanadas do governo federal, ou dos estados, procuraram minimizar os efeitos perversos dos projetos hidrelétricos, tendo como eixo de referência o fato desses projetos serem essencialmente conduzidos por empresas estatais (SANTOS, 2003).

Segundo a Resolução CONAMA, 001/86, a legislação brasileira exige o EIA/RIMA para aproveitamentos hidrelétricos com potência instalada superior a $10 \mathrm{MW}$.

O EIA e RIMA ficam à disposição do público que se interessar, na Biblioteca da FEPAM, respeitada a matéria versante sobre sigilo industrial, conforme estabelecido no CÓDIGO ESTADUAL DO MEIO AMBIENTE.É um documento que deverá ser apresentado de acordo com o Termo de Referência, que constitui um documento de orientação quanto aos procedimentos a serem seguidos na elaboração do mesmo, previamente acordado entre a FEPAM e a equipe contratada pelo empreendedor para a elaboração deste (FEPAN, 2002).

O Brasil possui o maior potencial para a geração de energia hidráulica do planeta Terra, no qual ainda faltam $50 \%$ a ser explorado. O fato das energias não renováveis serem caras, altamente poluentes, e estarem se acabando, tem feito com que a energia hidráulica, seja vista como uma importante fonte de energia renovável, sendo pouco poluente. (ABBUD; TANCREDI, 2010).

Segundo Sevá (2005), os reservatórios construídos para a geração de energia elétrica, são grandes estruturas, construídas pelo homem, as quais apresentam uma imensa acumulação de água. Estes reservatórios, como quais obras de grande porte, apresentam muitos impactos, econômicos, sociais, ambientais e culturais, os quais modificam comunidades inteiras, nos locais onde se instalam. Alguns impactos são irreversíveis, outros, conseguem ser amenizados através dos anos, por meio de ações entrópicas positivas, que consigam corrigir os danos causados (VECCHIA, 2012).

Vem se discutindo mundialmente os impactos causados por usinas hidrelétricas ao meio ambiente, com o objetivo de conscientizar a população da gravidade dos danos causados (INATOMI; UDAETA; 2005). Algumas instalações hidrelétricas não tem se mostrado sustentáveis, tanto no cenário nacional, quanto no Brasil (OLIVEIRA, 2009).

Os principais impactos químicos, físicos, biológicos, sociais e culturais, provocados pelas usinas hidrelétricas são:

- o Segundo Bortoleto (2001), os primeiros impactos das hidrelétricas ocorrem logo na construção do canteiro de obras, que modificam a economia local, pois com o aumento no uso de materiais e energia, estes sofrem inflação, o que prejudica financeiramente os 
moradores locais.

- o Impactos sociais como: o aumento inesperado da população, gerado pela vinda de trabalhadores de fora, gera problemas com o aumento de resíduos, tanto lixo, quanto resíduos sanitários (KOIFMAN, 2001).

- o A circulação intensa de veículos pesados danificam as vias publicas e modificam o transito (INATOMI; UDAETA, 2005).

- o Na maioria das vezes, os trabalhadores sofrem com precárias condições de trabalho (PANZERA, GOMES e MOURA, 2010).

- o Impactos hidrológicos, como a alteração da vazão, do fluxo da corrente, o aumento da profundidade, o alargamento do leito, a elevação do nível do lençol freático e a geração de pântanos (VECCHIA, 2012).

- o Impactos climáticos, como a alteração da umidade, temperatura, evaporação, ventos e precipitação (PANZERA, GOMES e MOURA, 2010).

- o Impactos no solo, como o assoreamento que provoca uma diminuição da vida útil do reservatório; a erosão, causando a perda do solo e das arvores (SEVÁ, 2005).

- o Impactos na flora, provocando a perda da biodiversidade, por aumentar a matéria orgânica e consequentemente diminuir os teores de oxigênio (VECCHIA, 2012).

- o Impactos na fauna, como perda da biodiversidade, pois exigem o realocamento de muitas espécies nativas, causando a morte de muitos animais, alguns deles em extinção (INATOMI; UDAETA, 2005).

- o Impactos históricos, como a perda de materiais arqueológicos, que estariam localizados nas áreas alagadas (PANZERA, GOMES e MOURA, 2010).

- o Impactos sociais, pois causa a realocação de famílias, muitas vezes ocorre a inundação de cidades inteiras, perdendo parte da sua cultura, das origens. Estas famílias normalmente são indenizadas e transferidas para outros locais, sofrendo também com a readaptação a uma nova vida (KOIFMAN, 2001).

- o O rompimento de barragens é um problema pouco frequente, mas possível, que causaria grandes inundações (PANZERA, GOMES e MOURA, 2010).

A realidade é que os benefícios energéticos são distribuídos às demais regiões do país e os impactos ambientais sociais e econômicos associados à construção e operação são absorvidos pelas regiões onde são construídas e operadas as usinas hidrelétricas (VECCHIA, 2012).

Cada rio possui características próprias, de fauna, flora, vazão e ciclos específicos, e mesmo quando estudos ambientais são realizados corretamente, muitas das vezes não é possível corrigir totalmente os danos causados pela construção das hidrelétricas. As ações de mitigação tem grande importância, para a redução destes impactos, mas não conseguem compensar de fato, os danos causados. Cada rio apresenta também diferentes tipos de população (ribeirinhos, indígenas, etc.) as quais são afetadas diretamente por construções deste porte (VIEIRA \& VAINER, 2010).

Para a construção de usinas hidrelétricas é necessário á integração de várias áreas do conhecimento como: engenheiros mecânicos, engenheiros eletricistas; engenheiros civis; engenheiros hidráulicos e engenheiros ambientais, dentre outros (ARTEAGA, 2010).

\section{CONSIDERAÇÕES FINAIS}

Os impactos causados pelas centrais hidrelétricas tornam-se toleráveis quando levado em conta a importância da energia hidráulica para a matriz energética mundial. Tendo em vista que a maioria dos impactos causados é local, é possível realizar ações mitigadoras para reduzir estes impactos.

A energia hidráulica permanece como uma fonte de energia renovável, pois não modifica as propriedades físico-químicas das águas, e permitem o retorno da água ao leito original do curso d'água alguns poucos quilômetros abaixo da barragem.

\section{REFERÊNCIAS BIBLIOGRÁFICAS}

ABBUD, Omar Alves; TANCREDI, Márcio 2010. Transformações recentes da matriz brasileira de geração de energia elétrica - causas e impactos principais. Disponível em: http://www12.senado.gov.br/ publicacoes/estudos-legislativos/tipos-de-estudos/ textos-para-discussao/td-69-transformacoes-recentes-da-matriz-brasileira-de-geracao-de-energia-eletrica-causas-e-impactos-principais. Acesso em: 02/02/2013.

AGÊNCIA NACIONAL DE ENERGIA ELÉTRICA (Brasil)-ANEEL. $1^{\circ}$ Ed. Brasilia-DF: Atlas de energia elétrica do Brasil: Energia Hidráulica. 2002 P.17-45 Disponível em: < http://www.aneel. gov.br/arquivos/pdf/livro_atlas.pdf pdf $>$ Acesso em: 
$23 / 12 / 2012$

AGÊNCIA NACIONAL DE ENERGIA ELÉTRICA (Brasil)- ANEEL. $2^{\circ}$ Ed. Brasilia-DF: Atlas de energia elétrica do Brasil: Energia Hidráulica. 2005 P. Disponível em: <http://www.aneel.gov.br/ aplicacoes/atlas/pdf/04-Energia_Hidraulica(2).pdf> Acesso em: 23/12/2012.

AGÊNCIA NACIONAL DE ENERGIA ELÉTRICA (Brasil) - ANEEL. $3^{\circ}$ Ed. Brasilia-DF: Atlas de energia elétrica do Brasil: Energia Hidráulica. 2008 P.58-61 Disponível em: <http://www.aneel.gov. br/arquivos/pdf/atlas_par2_cap3.pdf $>$ Acesso em: $23 / 12 / 2012$

ARTEAGA, Ronal Céspedes; BLANCO, Claudio Jusé Cavalcante; LEITE, Jandecy Cabral, 2010. Análise para diminuição das perdas no processo de Geração de Energia Elétrica da UHE - Balbina. Acesso em 03/02/2013.

BORTOLETO, E.M. 2001. A Implantação de Grandes Hidrelétricas: Desenvolvimento, Discurso e Impactos. Disponível em: http://www.maternatura. org.br/hidreletricas/biblioteca_docs/grandes $\% 20$ hidrelétricas.pdf Acesso em: 20/12/2012.

BRONZATTI, Fabrício Luiz; NETO, Alfredo Iarozinski. 2008 Matrizes energéticas no Brasil: cenário 2010-2030. Disponível em: http:// www.abepro.org.br/biblioteca/enegep2008_TN_ STO_077_541_11890.pdf

CANTARANI, Ricardo; BIANCHI, Alberto Jr.; COTRIM, Marcela; RUGAI Sérgio. 2009. Os riscos financeiros de empreendimentos hidrelétricos devidos á mudança climática. Disponível em: http:// www.abce.org.br/downloads/mudancas_climaticas_1.pdf. Acesso em: 28/12/2012.

CERPCHC - Centro Nacional de Referência em pequenas Centrais hidrelétricas: Fontes Renováveis. Hidráulica: A água. Disponível em: http://www. cerpch.unifei.edu.br/hidraulica.php. Acesso em: $30 / 01 / 2013$.

CICOGNA, M.A. 2003. Sistema de Suporte á Decisão para o Planejamento e Programação da Operação de Sistemas de Energia Elétrica. Disponível em: http://www.cose.fee.unicamp.br/cose/it511/ teses $\% 20$ unicamp/tese $\% 20$ Doutorado\%20marcelo. pdf. Acesso em: 02/01/2013.
FACURI, M.F. 2004. A Implantação de Usinas Hidrelétricas e o Processo de Licenciamento Ambiental: A Importância da Articulação Entre os Setores Elétrico e de Meio Ambiente no

Brasil. Disponível em: http://www.cerpch.unifei. edu.br/arquivos/dissertacoes/a-implantacao-usinas-hidreletricas-processo-de-licenciamento-ambiental. pdf Acesso em: 01/02/2013.

FEPAN. 2002. EIA/RIMA. Disponível em: http:// www.fepam.rs.gov.br/central/pdfs/eiarimainstabril2002.pdf

FERNADEZ, M. ; ARAUJO R.; ITO A.E.; 2009. Manual de hidráulica. Cap. 6 vertedouros. Pg87. $8^{a}$ edição. $6^{a}$ reimpressão. Editora EDGARD BLUCHER.

FREITAS, Marcos de; RANGEL, Diane; DUTRA, Luís. 2001. Gestão de recursos hídricos no Brasil: a experiência da Agência Nacional de Águas. Disponível em: http://www.bvsde.paho.org/bvsacd/encuen/ freitas.pdf Acesso em: 01/02/2011.

INATOMI, Tais Aya Hassan; UDAETA Miguel Edgar Morales. 2005. Disponível em: http://www. espacosustentavel.com/pdf/INATOMI_TAHI_ IMPACTOS_AMBIENTAIS.pdf. Acesso em: 11/02/2013.

INFO ESCOLA. Como funciona uma Hidrelétrica. Disponível em: http://www.infoescola.com/fisica/ como-funciona-uma-hidreletrica/. Acesso em: $01 / 02 / 2012$.

KOIFMAN, S. 2001. Electric Power Generation and Transmission: The Impact on Indigenous Peoples in Brazil. Disponível em: http://www.scielo.br/pdf/ csp/v17n2/4186.pdf Acesso em: 22/12/2012.

OLIVEIRA, M.P. 2009 Sistematização da análise de impactos ambientais em UHI. Disponível em: http:// www.lume.ufrgs.br/handle/10183/24127 Acesso em: 12/01/2013.

PANZERA, Arjuna C., GOMES, Artur E,Q., MOURA, Dácio G.2010. Moura. Impactos ambientais da produção de energia elétrica, Educação Ambiental Centro de Referência Virtual do Professor - SEE-MG / setembro 2010.

Resolução 01/1996 do Conselho Nacional do Meio Ambiente (CONAMA). Impacto ambiental. 
RESOLUÇÃO CONAMA N ${ }^{\circ} 001$, de 23 de janeiro de 1986. Disponível em: http://www.mma.gov.br/ port/conama/res/res86/res0186.html Acesso em: 01/02/2013.

Revista cultura e cidadania 2012 Artigos: Matrizes Energéticas do Brasil. Disponível em: http://revistaculturacidadania.blogspot.com.br/2012/05/artigos-matrizes-energeticas-do-brasil.html Acesso em: $10 / 12 / 2012$.

RUTH, P.S.. 2010 Tecnologias de Geração de Energia Elétrica: Geração Hidroelétrica. Disponível em: http:// ygo.pesqueira.ifpe.edu.br/didaticos/rd_II_ geracao1_hidroeletrica.pdf. Acesso em: 01/02/2013.

SANTOS, S.C. 2003 A geração hídrica de eletricidade no sul do Brasil e seus impactos sociais. Disponível em: http://ceas.iscte.pt/etnografica/docs/ vol_07/N1/Vol_vii_N1_087-104.pdf Acesso em: $13 / 01 / 2013$.

SEVÁ, O. 2005. Usinas hidrelétricas e termelétricas Roteiro experimental sobre as concepções e o modo de funcionamento e sobre algumas das consequências. Disponível em: http://www.ifch.unicamp.br/ profseva/972_apost_SEVA_uhe_ute.pdf Acesso em: 04/01/2013.

SOARES, R. B. R. 2013 Impacto Ambiental. Programa Educ@ar - USP. Disponível em: <http://educar.sc.usp.br/biologia/textos/impacto.htm > Acesso em 12/01/2013.

SOUZA, W.L. 2000. Impacto ambiental de hidrelétricas: uma análise comparativa de duas abordagens. Disponível em: http://www.ppe.ufrj.br/ppe/production/tesis/wlemgruber.pdf.

VECCHIA, R. 2012 Impactos provocados por usinas hidrelétricas. Disponível em: http://www.observadorpiraju.com.br/coluna_rodnei.asp?id=2763 Acesso em: 13/12/2012.

VIEIRA, Flávia; VAINER, Carlos. 2010 Manual do Atingido. Impactos Sociais e Ambientais de Barragens. Manual do Atingido - Impactos Sociais e Ambientais de Barragens. Acesso em: 13/01/2013. 